\title{
Una época dorada: las quintas de veraneo en el conurbano bonaerense. El caso Quinta Seré
}

\author{
Jimena Doval \\ Facultad de filosofía y letras, Universidad de Buenos Aires - \\ Dirección de Derechos Humanos, Municipio de Morón \\ jdova184@hotmail.com
}

Recibido: 16 de diciembre de 2009

Aceptado: 20 de octubre de 2010

\section{RESUMEN}

El objetivo de este trabajo es analizar el caso Quinta Seré (Morón, Provincia de Buenos Aires, Argentina) desde el punto de vista de la arqueología del paisaje. Observaremos el modo en el que el espacio y la arquitectura funcionaron como medio para comunicar mensajes de poder y estatus. La Quinta Seré no fue un caso aislado, sino que se incluyó dentro del proceso de apogeo de las quintas de veraneo de la clase alta en el conurbano bonaerense a principios del siglo XX, dentro del particular proceso social, político y económico que atravesaba la Argentina en ese momento. Se analizará la configuración formal de la mansión, su emplazamiento en relación con el espacio circundante, la articulación interna de su espacio, su función social, visibilidad y visibilización, patrón de movimiento y de accesibilidad. La integración entre el registro material y las fuentes documentales permitió observar que la construcción y organización de ese paisaje fue intencionada para lograr comunicar un mensaje de poder y status.

Palabras clave: Quinta Seré, paisaje, poder, arquitectura-status.

\section{A Gold Time: The Summer Houses in the Bonaerese Suburbs. The Quinta Sere's Case}

\begin{abstract}
The aim of this work is to analyze the Quinta Serés case (Morón, Buenos Aires) from the point of view of the archaeology of the landscape. We will focus on the ways that space and architecture become the means to communicate messages of power and status. The case Quinta Seré wasn't an isolated case, but it was included in the same process of the peak in the building of high class's summer country houses in the suburbs of Buenos Aires at the beginnings of the 20th century. This process can be understood if we analyze the social, politic and economic conditions Argentina went through at that time. We'll analyze the formal configuration of the mansion, its location and its relation with the surrounding space, the inner articulation of its space, its social function, its visibility and its possibility of becoming visible, the pattern of movements and the ways to get into it. The integration of material records and print sources gave us the possibility to see that the building and the organization of the landscape had an intention from the builders/users who attained to send a message of power and status.
\end{abstract}

Keywords: Quinta Seré, landscape, power, architecture-status.

Sumario: 1. Introducción. 2. Antecedentes. 3. Aspectos teóricos. 4. Metodología. 5. Reseña histórica. 6. La Quinta Seré: una mirada desde sus indicadores espaciales. 7. Consideraciones finales. 8. Referencias bibliográficas. 


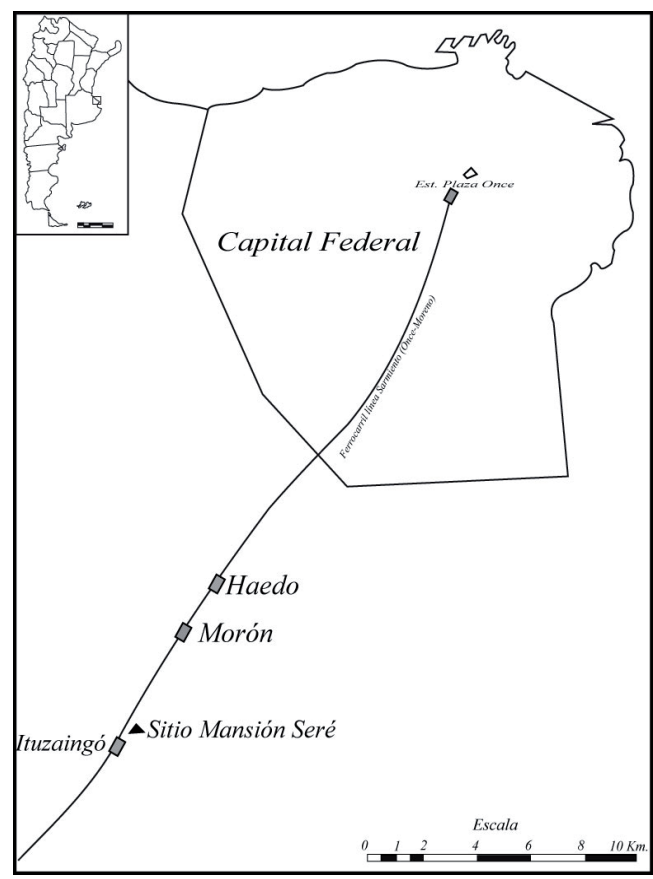

Figura 1: Ubicación geográfica.

\section{Introducción}

En el presente trabajo abordaremos el caso Quinta Seré/Mansión Seré (Morón, Provincia de Buenos Aires, Argentina) desde la perspectiva de la arqueología del paisaje. Nuestro principal foco de interés será desentrañar la organización espacial instaurada en su primera etapa de ocupación a finales del siglo XIX y principios del $\mathrm{XX}$. Tomando este caso de estudio como ejemplo de un proceso generalizado de instalación de quintas de veraneo en la zona oeste del conurbano bonaerense en esa época, proponemos evaluar cómo la construcción de estos paisajes reprodujeron el orden social imperante a nivel nacional y local, en una época en que el país crecía y se consolidaba mirando hacia Europa como modelo a seguir.

Este estudio se enmarca dentro de un objetivo más amplio que se dirige a identificar los cambios arquitectónicos y a nivel del paisaje que tuvo el sitio Mansión Seré, teniendo en cuenta sus diferentes usos y sistemas de saber-poder (Foucault 1989; 1992) que atravesaron el espacio. El sitio, ubicado en Morón, provincia de Buenos Aires (Figura 1), fue ocupado a finales del siglo XIX y principios del siglo XX por una familia de inmigrantes franceses que permaneció en la zona hasta 1949. Éste es el período en el que se centrará nuestro análisis. La Mansión Seré es más conocida por su uso, durante la última dictadura militar argentina (1976-1983), como Centro Clandestino de Detención dependiente de la Fuerza Aérea entre los años 1977 y 1978. La casona tuvo varios usos con anterioridad y posterioridad a ese período (Di Vruno et al. 2006; Doval et al. 2009). 
A partir de este caso nos centraremos en el entorno en el cual se instauró la Quinta Seré, cuáles fueron las características constructivas de la mansión y cómo el emplazamiento de esta estructura en un entorno rural funcionó como vehículo de comunicación de las relaciones de poder y status de las clases altas dominantes (Foucault 1989; DeMarrais et al. 1996).

Los resultados de este análisis nos permitirán llenar un vacío en cuanto a la historia de este lugar y a la carencia de investigaciones arqueológicas en el ámbito local. Además podremos profundizar sobre los cambios que atravesó el sitio a través de los años, sus diversas funciones y los significados que adquirió.

A continuación expondremos los antecedentes existentes en torno a la problemática planteada, los fundamentos teóricos, la metodología y una breve reseña histórica de la Quinta Seré comprendida en el contexto local y nacional. Para finalizar, presentaremos el desarrollo del análisis realizado y las conclusiones a las que hemos llegado en el curso de la investigación.

\section{Antecedentes}

Existen numerosos trabajos que han estudiado las relaciones de poder y su reflejo a través de la dimensión espacial (Nielsen 1995; Gallardo et al. 1995; DeMarrais et al. 1996; Moore 1996; Acuto 1999; Nielsen y Walker 1999). En arqueología histórica también se ha desarrollado esta temática para comprender la relación entre la construcción del espacio y el poder. Las investigaciones que se han llevado a cabo en América se han centrado en cuestiones similares a las de este estudio. En Latinoamérica, algunos trabajos se orientaron hacia el análisis de las casas del siglo XIX y XX, sus usos y cambios (Andrade Lima 1999; Funari y Zarankin 2002), hacia la comprensión de las relaciones de poder y dominación a través de la organización arquitectónica (Zarankin 1999; Zarankin y Niro 2006), hacia la construcción y reproducción de un orden social a través de la estructuración espacial (Senatore 2004); estas son algunas de las temáticas abordadas. En Norteamérica, los trabajos de Leone $(1984 ; 2005)$ en el jardín de William Paca y Beaudry et al. (1989) en Boott Mills, se dirigieron al estudio del espacio y su organización como medio de comunicar, controlar y manipular el medio social, configurándose la organización del espacio como una materialización de la ideología. Orser (1988), en las plantaciones de Carolina del Sur, estudió también la organización del espacio a través del análisis de la disposición de los edificios, su tamaño, su función y la distancia entre ellos. Los trabajos realizados en el marco de la arqueología del paisaje en Europa y América se exponen en algunos escritos, como los de Criado (1993, 1999; Criado et al. 2000) y Mañana et al. (2002), demostrando la potencialidad de esta propuesta de aproximación al estudio del espacio.

La instalación de la quintas en el conurbado bonaerense se ha tratado solamente desde la mirada de la Historia (Sáez 1998). Sin embargo, la arqueología histórica permitirá introducirnos más profundamente en la temática a partir de la integración de la cultura material y de las fuentes documentales. Así, la arqueología brinda herramien- 
tas que nos permitirán profundizar en aspectos omitidos por otras disciplinas y contar una parte de la historia ausente en las fuentes documentales y en la historia oficial.

\section{Aspectos teóricos}

La arqueología histórica tiene como objeto el estudio de la modernidad. El investigador se dirige al estudio de la misma modernidad de la cual él forma parte (Johnson 1996; Orser 1996; Funari 1999). Además, en contextos que tratan sobre historia reciente, se añade un plus de subjetividad en la mirada del investigador condicionando su mirada hacia el pasado (Shanks y Tilley 1987; Hodder 1988). Nuestra temática particular, vinculada a una etapa cercana en términos históricos, implica que las vivencias y memorias de nuestros familiares, conocidos o bien las nuestras, de forma directa o indirecta, se relacionen con el contexto histórico bajo estudio.

En el presente estudio partimos de la concepción de que el paisaje, como parte de la cultura material, es una construcción social que se crea, transmite y reproduce en la cotidianidad y dentro de un contexto histórico que lo determina (Shanks y Tilley 1987; Criado 1999; Thomas 2001; Leone 2005). Así, el contexto socio histórico condiciona a los individuos y ello se plasma en la cultura material. Como construcción social e históricamente determinada, la cultura material es depositaria de diversos significados y vehículo de comunicación. Esto no implica un papel pasivo de la misma, sino que envuelve una relación dicotómica entre los individuos y la cultura material. En este sentido, los individuos crean un paisaje y éste vuelve recurrentemente como un modo de sociabilización (Tilley 1996).

La relación entre la construcción social del paisaje y la transmisión de un mensaje de poder será abordada a través de la idea de DeMarrais et al. (1996) de que la ideología es parte de la cultura y por lo tanto se materializa. Esta materialización de la racionalidad e identidad de sus constructores/usuarios se refleja en la arquitectura y en la organización del espacio (Foucault 1989).

La arqueología del paisaje (Criado 1991, 1993, 1999; Mañana et al. 2002) nos brinda las herramientas fundamentales para nuestro análisis, ya que éste se concibe como un campo de discurso que se expresa a través de los elementos materiales y su distribución. Ese discurso puede descifrarse a través de la lógica espacial descompuesta mediante distintas variables de estudio.

La utilización de diversas fuentes de información tales como la fotografía, planos, la memoria oral, diversas fuentes escritas y los elementos de la cultura material, nos permitirá abordar la reconstrucción histórica y espacial a través de múltiples experiencias (Gnecco 1999; Hodder 1999; Webmoor 2005). Además, la utilización de diferentes fuentes de información implica la interrelación constante entre la cultura material y las fuentes documentales, que requerirán una lectura crítica y una constante retroalimentación entre ellas. Esta integración nos permitirá comprender el rol activo del registro material y documental en cada contexto histórico particular (Beaudry et al. 1996; Orser 2000; Wilkie 2006). 
Los aspectos teóricos aquí mencionados nos permitirán comprender la configuración del paisaje a principios de siglo XX como el reflejo de la objetivación de una intención, sentido y racionalidad de una clase social dominante. Esta clase social de alto poder adquisitivo, en su mayoría inmigrante, dejó una marca en el espacio como símbolo de su poder y su estatus. El caso de Quinta Seré puede demostrar cómo a través del espacio y la arquitectura se reflejó un modelo de país y de sociedad imperante en esa época.

\section{Metodología}

La arqueología del paisaje (Criado 1999) nos brinda las herramientas que nos permitirán introducirnos en la lógica no visible de la Quinta Seré. Para ello será necesario descomponer el espacio a partir de los siguientes indicadores: la configuración formal de la quinta y la mansión, su emplazamiento en relación con el espacio circundante, la articulación interna de su espacio, función social, visibilidad y visibilización, patrón de movimiento y de accesibilidad.

Los datos serán extraídos a partir de dos fuentes de información. Por un lado, la cultura material compuesta de material excavado y los cimientos descubiertos de la estructura principal de la mansión y el relevamiento superficial de los diferentes elementos materiales y naturales (otras construcciones, caminos, disposición de arboledas). Por otro lado, las fuentes documentales, entre las que se incluyen: planos catastrales de 1949 y $1959^{1}$, plano del camino afirmado Morón-Luján $1924^{2}$, un archivo fotográfico de 128 imágenes $^{3}$, la memoria oral y diversos documentos escritos (testamento de Juan Seré, compra-venta y permuta de terrenos, sucesión de María Etcheverts, etc.)

El registro material permitirá la observación de las dimensiones y disposición de los recintos de la casa y los objetos y materiales de construcción que muestran la calidad y la procedencia de los materiales. El relevamiento de otras estructuras, elementos del paisaje y materiales en superficie, posibilitará relevar en forma integral el espacio, las construcciones, los caminos y sus características.

Las fuentes documentales, entre algunas de las contribuciones más sobresalientes, contribuirán a acceder a información como memorias, percepciones y valoraciones de ese espacio, precisar fechas, observar características no conservadas a través de la cultura material.

Los datos que nos brinda la evidencia material serán integrados a la información documental, lo que permitirá extraer mejores interpretaciones.

1 «Mensura de cuatro fracciones de terreno situadas en cuartel $2^{\circ}$ del Pdo. De Morón (Prov. De Buenos Aires), propiedad de doña Leocadia Seré de Capdepont o Leocadia Seré y Etcheverts de Capdepont», 101100-49, Dirección de Geodesia, Ambiente y Planos, Buenos Aires, febrero 1949. «Mensura de los terrenos situados en Ituzaingó, Partido de Morón, propiedad del Centro de Previsión Social de la Ciudad de Buenos Aires», Dirección de Catastro de la Ciudad de Buenos Aires, 1959.

2 Catastro del camino afirmado de Morón a Luján. Partido de Morón, estado de Catastro diciembre de 1924.

3 Archivo alojado como parte del Archivo documental del área de investigación de la Dirección de Derechos Humanos de Morón. 


\section{Reseña histórica}

\subsection{Contexto local y nacional}

La instalación de quintas en la ciudad de Morón (Provincia de Buenos Aires), tuvo su apogeo entre 1880 y 1930, período en el que la zona comenzó a poblarse por familias aristocráticas que adquirían grandes parcelas de tierra. Este proceso sucedió de manera generalizada en toda la zona, acrecentándose a partir de la llegada del ferrocarril a Morón e Ituzaingó en 1859. Se convirtió entonces en un lugar turístico y de esparcimiento a donde llegaban numerosas familias porteñas; además, esta región se consideraba una zona con un microclima benévolo para las enfermedades de las vías respiratorias como el asma. Estas quintas se erigieron como grandes monumentos arquitectónicos en medio de un paisaje rural, siendo la población estable de la zona en su mayoría rural y con un porcentaje alto de españoles, italianos y franceses. La ocupación de las quintas de veraneo en el conurbano bonaerense se configuró como un símbolo de la generación de los ochenta y de una minoría que anhelaba el progreso y la modernización, tal como lo experimentó la sociedad europea (AAVV 1998; Sáez 1998). Así, la zona pasó de ser un área rural dedicada al cultivo de trigo, a un entorno elegido por familias adineradas para instalar sus ostentosas mansiones y sitios de descanso de fin de semana.

Para comprender cómo se dio este proceso es necesario remontarse hasta mediados del siglo XIX, cuando se estaba consolidando la idea del Estado-Nación basada en una política liberal y en el modelo agro exportador. En ese momento comenzó un fuerte crecimiento demográfico a partir de la entrada de grandes cantidades de inmigrantes europeos. Por otro lado, se venía dando un proceso que conjugaba la adjudicación de tierras a familias acaudaladas con la avanzada militar hacia el sur de la frontera con el indígena. Se pretendía ocupar aquellas tierras «despobladas» en pos de la expansión ganadera de acuerdo con el proyecto económico-político liberal para aumentar el comercio exterior. De este modo, la adjudicación de grandes parcelas de tierra a familias acaudaladas proporcionaba dos ventajas al Estado. En primer lugar, éstas invertirían en la explotación ganadera, y en segundo lugar contribuirían a la ocupación del «desierto» (Barba 1998). La familia Seré no fue ajena a este proceso e instalaron una de las primeras estancias al sur de la «frontera», una frontera de la incipiente nación argentina que comenzaba en Buenos Aires y terminaba en Mendoza, más allá de la cual se extendía el «desierto». La conquista de ese «desierto» mediante la campaña organizada por el General Roca constituyó un hecho genocida que arrasó la población indígena de la región en busca de la modernización del nuevo Estado en crecimiento (Gomez Romero 2006). 


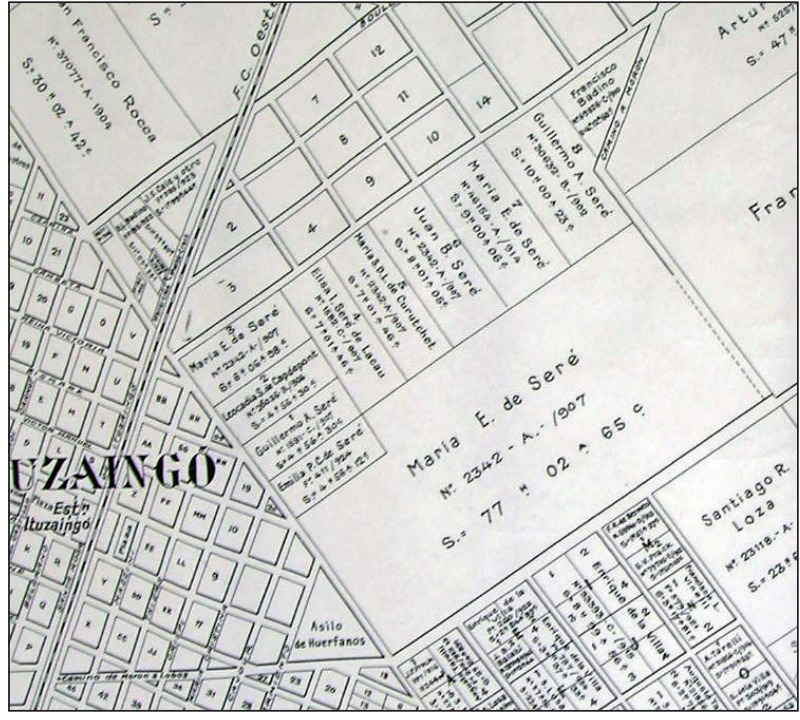

Figura 2: La Quinta Seré y su entorno, año 1924. (Archivo DD.HH., Morón N³333).

\subsection{La familia Seré}

En 1862, Juan Seré arribó al país desde Moncayole, pueblo del Bajo Pirineo francés. En Argentina conoció a María Etcheverts, proveniente de la Baja Navarra (Francia), con quien contrajo matrimonio, asentándose posteriormente en Capital Federal. En dos o tres años hicieron una pequeña fortuna mediante la actividad comercial, y antes de 1870 adquirió 15.000 ha en el actual partido de Lincoln (Provincia de Buenos Aires). La estancia «La Leocadia» fue una de las primeras en la zona, asentándose por fuera de la zona de frontera y dedicándose a la cría de ganado y caballos de polo. Años después aumentó su fortuna con la instalación de la segunda fábrica de bolsas de arpillera en el país y una fábrica textil en Capital Federal, en la zona de Parque Patricios (Bénard de Arichuluaga 2000).

En esta misma época, la familia Seré adquirió 56 ha en Morón, cerca de la ciudad de Santa Rosa (hoy Ituzaingó), estableciendo la Quinta Seré. En la fracción de tierra que Juan Seré deja como herencia a su hija Leocadia ${ }^{4}$, fue construido un palacete, diseñado por un arquitecto francés, que se conoció como Mansión Seré (Bénard de Arichuluaga 2000). En los terrenos colindantes Guillermo y Luciano Seré erigieron sus respectivas mansiones. En la década de los 40 comenzó la parcelación y venta de los terrenos pertenecientes a los Seré, sobre los cuales se conformó el actual barrió Seré. Las 11 ha pertenecientes a Leocadia Seré fueron adquiridas en 1949 por el Centro de Previsión Social de la Ciudad de Buenos Aires. En este momento, con posterioridad a la gran crisis económica mundial de los años 30 y a la caída del modelo agro exportador, se da en toda la zona la parclación de las grandes fracciones de terrenos de las viejas quintas, lo que produjo un rápido crecimiento poblacional y urbano.

\footnotetext{
4 Testamento Juan Seré 1893, No 100857, Ciudad de Buenos Aires.
} 


\section{La Quinta Seré: una mirada desde sus indicadores espaciales}

La fracción perteneciente a Leocadia Seré, sobre la cual versará este análisis, se componía de 11 ha obtenidas por la herencia de sus padres y la permuta y compra de tierra a los demás herederos. Esa fracción, ubicada sobre el vértice noreste, tuvo y tiene un lugar privilegiado respecto del resto por la cercanía y fácil acceso a las dos arterias de circulación principales: la Avenida Rivadavia con dirección esteoeste, como camino paralelo al ferrocarril (línea Sarmiento ramal Once-Moreno) y que comunica con el centro de la Ciudad de Buenos Aires y el acceso a la ruta 7 hacia Luján, y la calle Blas Parera, que se configuró como la otra vía de circulación importante, sobre la que se asentaba el frente de la quinta y las vías de acceso a la misma. Además, esta calle corría en dirección norte-sur, lo que permitía el cruce del paso a nivel del ferrocarril mediante la denominada barrera 78. Otra de las virtudes del emplazamiento de los terrenos era su proximidad a la zona céntrica de Ituzaingó: su centro comercial, la plaza, las escuelas, la parroquia y la estación de ferrocarril (Figura 2).

En las primeras décadas del siglo XX, Leocadia y su marido levantan allí una quinta con gran cantidad de árboles frutales, un sector con caballerizas, un tanque australiano, dos casas para los caseros de características arquitectónicas modestas (Vecina I com. pers. 2008; Vecina II com. pers. 2008) ${ }^{5}$, dos pequeñas construcciones que posiblemente fueran pañoles y una gran mansión de dos plantas ubicada sobre el sector noreste del predio. Esta construcción, de estilo francés, se constituyó como un monumento de alta visibilidad en el paisaje circundante, teniendo en cuenta la baja población de la zona, la poca urbanización y la dimensión de los terrenos circundantes. Esos terrenos colindantes pertenecían a otras familias adineradas y poderosas, como los Calé, Agrelos, Barbesi, etc. (Vecino III com. pers. 2007; ver Figura 2).

Las características constructivas de la casona, la espectacularidad de su estilo y algunos de sus materiales constructivos, así como también su ubicación, permitieron que la mansión tuviese una gran visibilización desde el exterior. Era perceptible desde las principales vías de circulación, como la actual calle Blas Parera, a $60 \mathrm{~m}$, y desde la actual Av. Rivadavia, a 50 m, como también desde el ferrocarril. Ello pudo rescatarse a través de planos, del registro fotográfico de 128 imágenes donadas por los vecinos, de la memoria oral de vecinos, los testimonios de ex detenidos desaparecidos y de la evidencia material rescatada durante el proceso de excavación.

Los materiales de construcción de la casona fueron en su mayoría de origen francés y entre los más destacados se encuentran las baldosas cerámicas Pierre Maurel Aubagne, las tejas provenientes del puerto de Marsella, la variedad de baldosas graníticas y de cemento Martin Freres, y el revestimiento de la chimenea de cerámica refractaria «Depose-vitry-le Francois». Asimismo la utilización de cemento portland para el revoque de la terminación exterior, las molduras de cornisas y ventanas, y para columnas, los pisos flotantes de madera (pinotea), los muebles de madera maciza, las escalinatas de mármol de Carrara, las herrerías con un gran trabajo artesanal, las

5 Las comunicaciones personales y datos del archivo audiovisual se englobaron bajo el nombre genérico de «Vecino» para resguardar la identidad de las personas. 


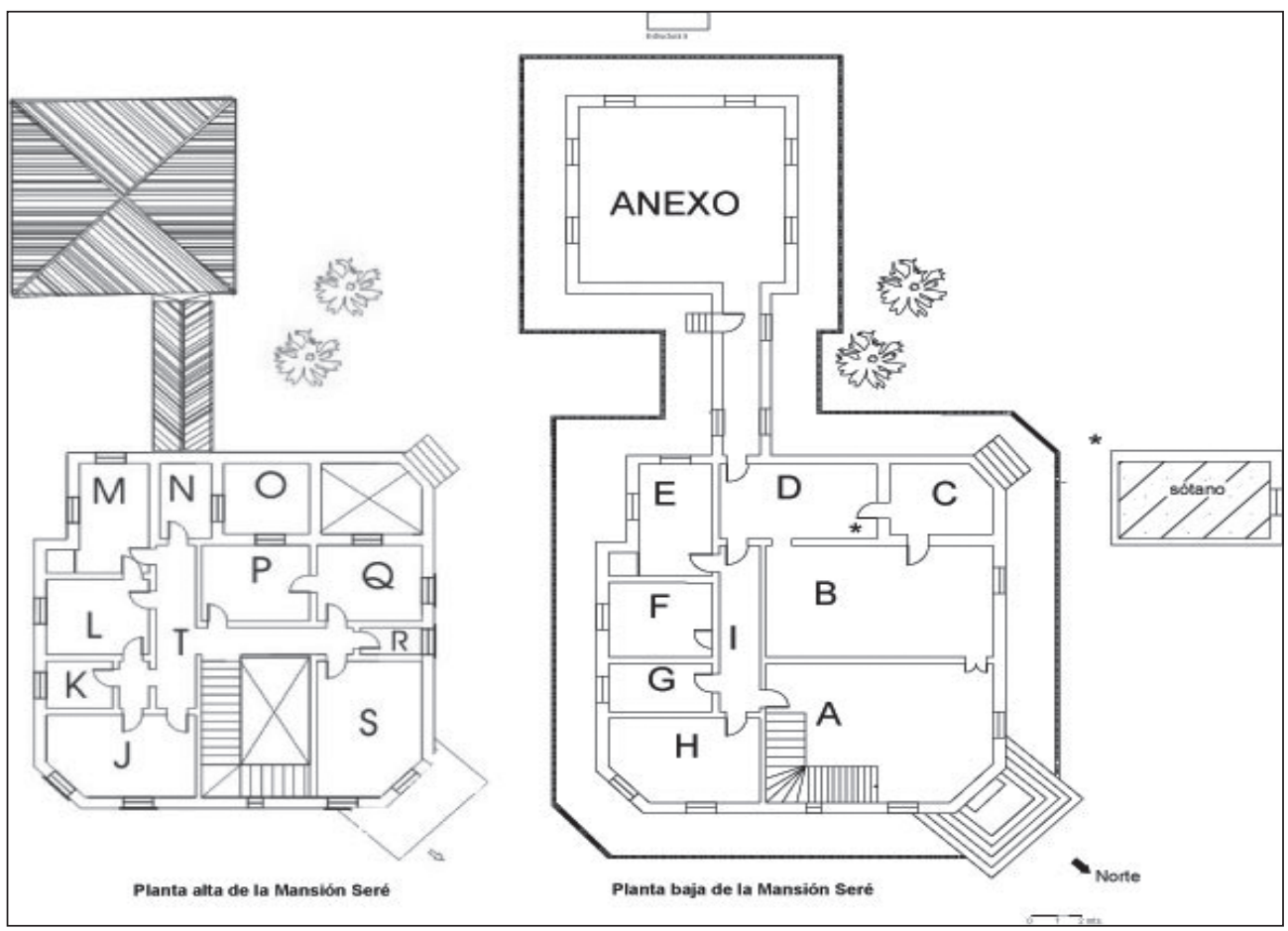

Figura 3: Reconstrucción de la planta.

carpinterías de madera fina importada (cedro y roble), etc. son reflejo de un poder adquisitivo y de un estatus particular. Todos estos elementos contribuyeron a la magnificencia y a la espectacularidad del edificio. Esos materiales tuvieron una presencia recurrente en las construcciones pertenecientes a una clase acomodada de mediados del siglo XIX y principios del siglo XX en las principales ciudades de Latinoamérica, debido al desarrollo de las redes comerciales entre los principales puertos de Sudamérica y Europa (Schavelzón 1991, 1999). La utilización de esos materiales en casonas del conurbano bonaerense implicó un costo adicional comparado con los de la Ciudad de Buenos Aires, dada la necesidad de transporte a una distancia de más de $30 \mathrm{~km}$ del puerto.

Las dimensiones y características de los espacios de la casona pudieron observarse mediante una planta generada a partir del relevamiento de los cimientos de la mansión y de la reconstrucción arquitectónica de la planta alta sobre la base de fotografías, croquis de ex detenidos desaparecidos (sobrevivientes a su detención durante la última dictadura militar argentina) y relatos de vecinos (Doval et al. 2009). Todo ello permitió determinar que la mansión tenía dos pisos y un pequeño sótano. La planta baja estaba compuesta por seis habitaciones y un baño $\left(196,38 \mathrm{~m}^{2}\right.$ en total) y el acceso a un sótano $(6 \mathrm{~m} \times 3 \mathrm{~m})$. En la planta alta había siete habitaciones y dos baños $\left(227,42 \mathrm{~m}^{2}\right.$ en total). Además, el edificio principal contaba con una construc- 


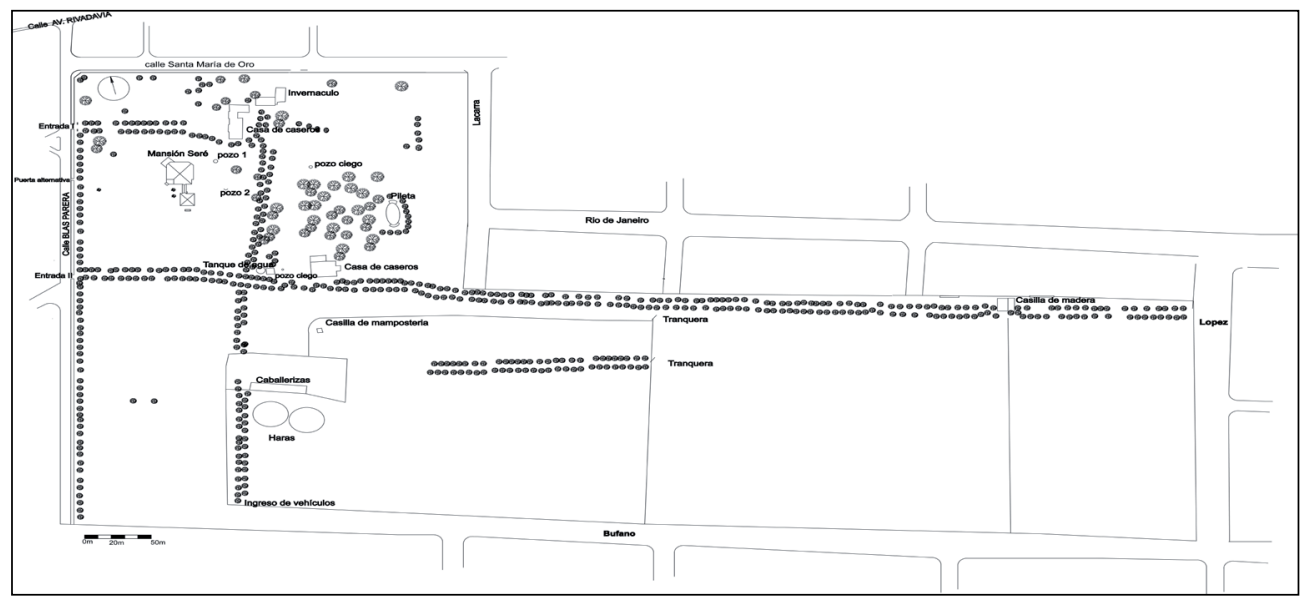

Figura 4: Plano de la fracción norte de la Quinta Seré.

ción aneja de una sola planta que se utilizaba como sector de servicio (Figura 3). En este último sector no ha sido posible determinar la división interior de sus espacios a través de los trabajos de excavación, pero se estima una superficie total de $76,22 \mathrm{~m}^{2}$ y, a través de relatos orales (Familia Seré Capdepont com. pers. 2000; Vecina I com. pers. 2008; Vecina II com. pers. 2008), podríamos contemplar la existencia de cuatro espacios: un baño, cocina y despensa, sector de lavado y planchado y un comedor.

A partir de la observación de las características espaciales de los recintos de la mansión, resalta la superioridad en tamaño, en comparación con los demás, de los recintos denominados A y B. Este hecho tiene su explicación en la función social de los mismos. Éstos se constituían como las habitaciones más cercanas al frente de la casona, a las que se tenía acceso mediante la entrada principal (A) y una entrada secundaria (B), y fueron utilizados como ámbito de reuniones y eventos sociales. De este modo resalta su carácter público frente a la privacidad de otros recintos, sobre todo el sector de la planta alta destinado a dormitorios y el sector trasero de servicio. La alta segmentación de los espacios y el control de la circulación mediante un pasillo distribuidor (recintos I y T), permitió separar las áreas vinculadas a las distintas esferas y funciones (uso público, uso privado y sector de servicios). Los espacios cercanos a la entrada principal se convirtieron en el área de sociabilización, mientras que los sectores más relegados, como el sector de servicios y dormitorios, contaron con un acceso restringido, lo que les permitió tener un carácter más privado y volcado hacia la esfera de lo doméstico. Un análisis de sintaxis espacial nos permitirá seguir avanzando en la comprensión de la organización y de la función espacial dentro de la casa (Hiller y Hanson 1984; Blanton 1994).

En cuanto a las demás construcciones de la quinta, mientras que se conoce su ubicación y dimensiones a través del plano catastral de 1959, la fotografía aérea 1966 y la memoria oral, se desconocen detalles constructivos, con excepción de algunos casos. Así el tanque de agua, la piscina y los pilares de la entrada principal son estruc- 


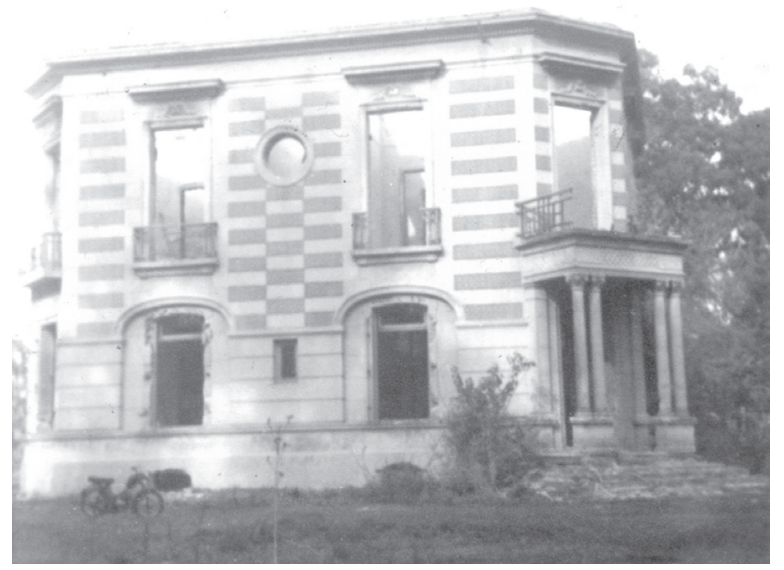

Figura 5: Fotografía $\mathrm{N}^{\circ} 16$, Archivo DD.HH., Morón (1979).

turas actualmente en pie, lo que permite observar sus características formales. Los relatos nos permiten extraer algunas descripciones de los espacios menos conocidos, aunque sin demasiado detalle. Esos relatos hacen hincapié en la modestia de las dos casas para los caseros frente a la espectacularidad de la mansión. Los planos indican que estas construcciones no superan los $260 \mathrm{~m}^{2}$ (en el caso de la mayor), frente a los $520,80 \mathrm{~m}^{2}$ totales de la construcción principal. La fotografía $\mathrm{N}^{\mathrm{o}} 21$ de 1972 refleja una de esas dos construcciones en la forma de un sencillo chalet. La caballeriza, según algunas menciones, era una construcción de troncos y paja en la que alojaban a caballos de polo que criaban en las estancias del interior.

Lo que resalta en cuanto a la conformación formal del espacio de la quinta Seré es el parque compuesto por una gran arboleda (acacias, fresnos, pinos, eucaliptos, moreras, ombús, palmeras, etc.), que refuerza la segmentación espacial de los distintos sectores y la delimitación de las vías de circulación internas. Además, la disposición de las arboledas permitió implantar estrategias que manipularon la percepción sobre el paisaje, monumentalizando algunos espacios y ocultando otros (Criado 1991; Leone 2005). Así, podemos observar en el plano confeccionado a partir de planos catastrales, la fotografía aérea y el relevamiento superficial (Figura 4), que la disposición del parque resaltó la mansión hacia el exterior por encima de las otras construcciones.

Como se ha descrito anteriormente, la construcción principal presentaba características y acabados que la convertían en un monumento arquitectónico de grandes dimensiones, que rompía la monotonía de un entorno rural homogéneo y se constituía como el símbolo de la explosión de Morón e Ituzaingó como lugar residencial y de veraneo (Figura 5). La ubicación de la casona, sus características constructivas y la distribución de los elementos del paisaje, permitía una visibilización privilegiada con respecto a las demás construcciones existentes en el predio. Las características constructivas del resto de las edificaciones y su posición en el predio, más alejadas de las arterias de circulación (Blas Parera y Av. Rivadavia), a una distancia de más de 20 $\mathrm{m}$ hacia el sur de la mansión y ocultas tras una espesa arboleda, generaron una baja visibilización de las áreas de servicio y más privadas de la quinta. 


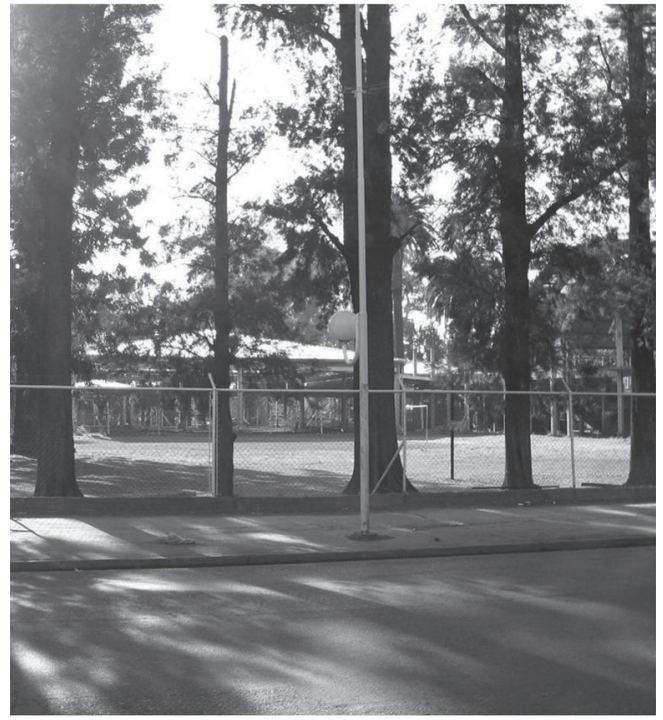

Figura 6: Vista actual desde la calle Blas Parera.

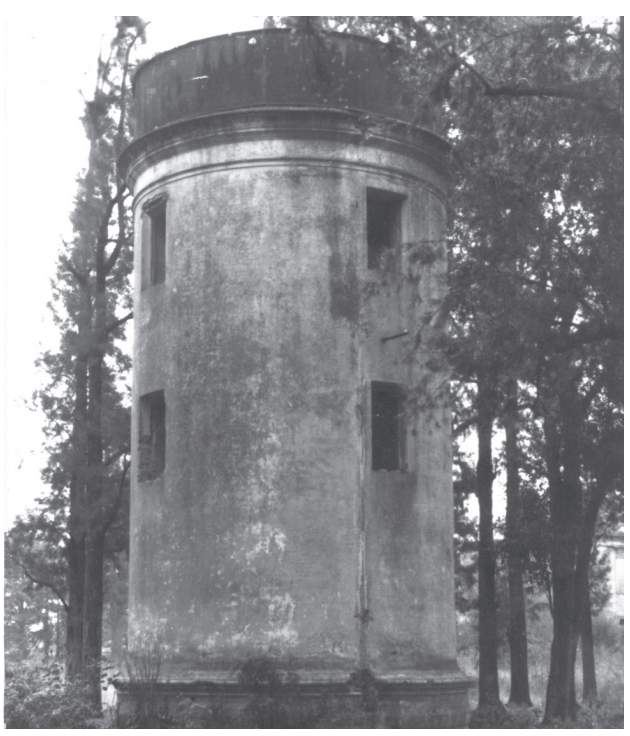

Figura 7: Tanque de agua. (Fotografía $\mathrm{N}^{\mathrm{o}} 87$, Archivo DD.HH., Morón).

A partir del techado definitivo, instalado en 2006 y que contendrá el museo de sitio, fue posible darse cuenta del impacto visual que tuvo la Mansión estando en pie, dada sus similitudes en altura y dimensiones con el techo original. Esto resalta más aún si tenemos en cuenta que en la actualidad estamos en un contexto totalmente urbanizado (Figura 6). También, los relatos de algunos vecinos (com. pers. 2001 a 2008), demuestran el impacto que generó esa construcción en el espacio:

«eran gente riquísima, en una época donde los que tenían se notaba mucho más abiertamente. Este era un lugar medio paradisíaco cuando estaba todo entero... era un palacio» (Vecina IV com. pers. 2007).

En cuanto a las condiciones de visibilidad desde la quinta, resaltan dos espacios desde los cuales se tenía una posición privilegiada sobre el resto. En primer lugar la mansión: su altura (aproximadamente $7 \mathrm{~m}$ ), la ubicación geográfica sobre el terreno, la disposición de dos ventanas en cada uno de sus cuatro laterales y dos balcones en las ochavas Norte y Este, y una pequeña terraza en el sector Oeste (recinto O), brindaba una visión panóptica (Foucault 1989) del entorno. Ello permitía el control sobre las principales vías de circulación y acceso y sobre parte del terreno circundante dentro y fuera de la quinta. La construcción aneja a la construcción principal, ubicada en el sector sureste y destinado a tareas de servicio, dadas sus características constructivas, tenía una baja visibilidad desde su interior y pocas perspectivas de visibilización, a pesar de su contigüidad con la mansión. Esto apoya la existencia de una jerarquización de los espacios de acuerdo con su función.

En segundo lugar, el tanque de agua fue otro de los lugares privilegiados en cuanto a la visibilidad. En el plano (ver Figura 4) se puede observar que esta construcción 
estaba ubicada en un lugar central dentro del predio, con una altura similar a la casona y con ventanas en su parte alta hacia los cuatro puntos cardinales, permitiendo una amplia visualización sobre el resto del terreno (Figura 7).

La accesibilidad y el patrón de movimiento observado nos permiten seguir diferenciando la función de los espacios dentro de la quinta. En este sentido, se podrían diferenciar aquellas vías de acceso principales de las de servicio. Las vías de acceso principales se encontraban en el frente de la mansión a unos 50 metros de distancia, colindantes con la actual calle Blas Parera. Llamaremos entrada I a la ubicada en el sector noreste. Ésta estaba constituida por cuatro pilares de grandes dimensiones (actualmente en pie) que entonaban con el estilo arquitectónico de la casa, un portón de hierro en el centro para el acceso de vehículos y una entrada a cada lado del portón. Llamaremos entrada II a aquella ubicada a $120 \mathrm{~m}$ aproximadamente de la I, en dirección sudoeste. La misma contaba con dos pilares de características similares a los de la entrada I y un portón para acceso de vehículos (ver Figura 4). Aunque ambas entradas se hallaban sobre la misma línea, es posible que hayan tenido diferente importancia. Por un lado, ambas se encuentran en una posición simétrica con respecto a la casa, sin embargo, la entrada I se encuentra más cercana y en dirección a la entrada principal de la mansión. A través de los trabajos arqueológicos se hallaron fragmentos de un piso de ladrillos que corresponderían al camino que se dirige desde la entrada I a la entrada principal de la casa y la rodea sobre las alas noroeste-noreste y noreste-sudeste. Podríamos entonces plantear que la entrada I funcionó como la entrada principal, y la entrada II tuvo una función secundaria. Además, sobre la fotografía aérea de 1966 es posible observar las huellas de circulación que unen la entrada II con el acceso trasero de la casona como primera parada, y luego en dirección al anejo y al fondo de la quinta.

De acuerdo con relatos de los vecinos, entre la entrada I y II, pudo existir una entrada alternativa precaria (Vecina I 2008) que habría sido abierta por los caseros. Tendríamos que indagar si esa entrada se abrió durante la ocupación de la familia Seré o posteriormente. Lo mismo sucede con las dos tranqueras ubicadas en el sector este del terreno existentes en el plano catastral del año 1959. Podemos suponer, y algunos relatos lo refuerzan, la existencia de por lo menos otra vía de acceso alternativa en el sector sureste, que con certeza fue utilizada en momentos posteriores por los vecinos como atajo dentro del predio. Seguramente el personal de servicio no utilizaría las mismas vías de acceso que los señores Seré, diferenciando entre accesos principales y alternativos de acuerdo con el estatus y a la función. También pudo existir algún acceso interno que comunicase la quinta de Leocadia Seré con la contigua perteneciente a su hermano Guillermo Seré, aunque aún no se ha podido comprobar. En cuanto a la comunicación entre las mansiones, existe en la memoria oral una mención recurrente que plantea la existencia de túneles que comunicaban estas construcciones y que se ha mantenido a través de los años en la memoria colectiva de la comunidad local. Aunque no se descarta la posibilidad de la existencia de los mismos, no existe aún una evidencia material que lo sustente ni algún relato que permita ubicarlos con exactitud. La quinta contaba con al menos cuatro pozos negros (dos de ellos se han hallado), los cuales pueden confundirse fácilmente con lo que comúnmente se imagina como el acceso a un túnel. Esto se ha repetido en otros sitios con fechas similares y 
con menciones de la comunidad acerca de la existencia de túneles (Schavelzón 2005). Es un tema interesante para seguir indagando, ya sea desde la prospección sobre el terreno en busca de evidencias materiales, como desde el relevamiento de memorias e historias vinculadas a las construcciones subterráneas que permitieron la construcción y reproducción de la memoria colectiva.

De acuerdo con las observaciones en pos de las variables anteriormente presentadas, podemos considerar que la disposición de las construcciones en el paisaje no actuó como algo casual, sino que tuvo una intencionalidad por parte de sus constructores/usuarios. La ubicación de la construcción principal de la Quinta Seré, su disposición, características formales, visibilidad, visibilización y accesibilidad, se corresponden con la identidad y posición socio económica de sus dueños. De ese modo, la arquitectura se convirtió en un modo de comunicación del poder y estatus de la familia Seré. Las diferencias funcionales existentes en el espacio marcan una clara segmentación entre los sectores vinculados con lo doméstico, con lo privado y/o a áreas de servicio y aquellos sectores vinculados con la sociabilización y el uso público. Esto pudo lograrse a partir del control de los accesos y los movimientos a través de caminos, pasillos, el control visual, la disposición de cada uno de los elementos constructivos y naturales de modo intencional en el paisaje.

\section{Consideraciones finales}

El proceso de instauración de quintas en la zona oeste del conurbano bonaerense se contextualiza durante la consolidación del Estado Nación y la instauración del modelo agro exportador. Además este proceso se acompañó por la gran afluencia de migrantes provenientes de Europa y la configuración de una clase dominante con alto poder adquisitivo. Esta clase alta emergente, poseedora de grandes extensiones de tierras en la provincia de Buenos Aires y otras partes del país, manifestaron su status social a través de la construcción del paisaje. Así, consideramos que la Quinta Seré fue la materialización de la ideología imperante en la clase hegemónica de principios del siglo XX. En este sentido, fue el reflejo de la intención de sus constructores/usuarios de transmitir determinado mensaje dentro de un contexto histórico, político y social particular. Al mismo tiempo funcionó como un modo de sociabilización, tanto para sus ocupantes como para todo aquel que percibiera ese espacio. En este sentido, la elección de una estrategia de monumentalización del espacio logró comunicar un mensaje de alto estatus y poder. Como resultado de esa organización y construcción del paisaje intencionadas, vemos que existió una jerarquización y segmentación de los espacios dentro de la quinta y de la casona. Esto logró diferenciar las áreas públicas de las privadas, separando las áreas de sociabilización sin restricciones de acceso, de aquellos sectores reservados a lo doméstico y a lo íntimo. En ese mismo sentido se resaltó la distinción entre aquellos sectores que se hacían visibles frente a otros invisibilizados, diferenciando espacios de alto estatus y bajo estatus. En consonancia con ello, se manipularon intencionalmente las formas de percepción visual y los patrones de movimiento y accesibilidad a los distintos lugares. 
La Quinta Seré no fue un hecho aislado, sino que es posible remontarse a numerosos casos similares (Instituto histórico de Morón 1997; AAVV 1998). El avance de la urbanización arrasó la mayoría de esos lugares quedando solo algunos restos de estancias, las memorias de los descendientes de estas familias y de los vecinos de la época.

Este trabajo es una primera aproximación al espacio ocupado por la Quinta Seré. Los resultados obtenidos plantean nuevos interrogantes y la necesidad de la profundización de algunos aspectos. Finalmente, la persecución de un objetivo más amplio nos anima a seguir avanzando para determinar cómo este mismo espacio fue cambiando y resignificándose a partir de los diferentes usos y contextos por los que atravesó.

Agradecimientos: A Alicia Tapia por animarme a publicar el trabajo y abrirme nuevas perspectivas. A Pablo Giorno por su lectura crítica, sus contribuciones y discusiones enriquecedoras en el trabajo cotidiano. A mis compañeros de equipo de investigación.

\section{Referencias bibliográficas}

AAVV

1998 «Síntesis histórica del Partido de Morón, Buenos Aires», Instituto Histórico de Morón. Ms.

Acuto, Felix

1999 «Paisaje y dominación: La constitución del espacio social en el Imperio Inka», en Sed non satiata. Teoría en la arqueología latinoamericana contemporánea, A. Zarankin y F. Acuto, eds., pp. 33-75. Buenos Aires: Ediciones del Tridente.

BARBA, Fernando

1998 «El avance de la frontera y la política de tierras públicas como condiciones al establecimiento de las estancias al sur del Salado». Revista de Historia Bonaerense 17: 47-50.

Beaudry, Mary C., Lauren J. Cook y Stephen A. Mrozowski

1989 «The Lowell Boott Mills Complex and its Housing: Material Expressions of Corporate Ideology». Historical Archaeology 23 (1): 19-32.

1996 «Artifacts and Active Voices: Material Culture as Social Discurse», en Images of the Recent Past. Readings in Historical Archaeology, C. Orser, ed., pp. 273-310. Maryland: Altamira Press.

Bénard de Arichuluaga, Magdalena

2000 La familia Seré. Los vascos Eukaldunak. Buenos Aires: Fundación Vasco Argentina.

BLANTON, Richard

1994 Houses and Household. A Comparative Study. Nueva York: Plenum Press. 
Criado Boado, Felipe

1991 «Construcción social del espacio y reconstrucción arqueológica del paisaje». Boletín de Antropología Americana 24: 5-29.

1993 «Límites y posibilidades de la Arqueología del Paisaje». SPAL 2: 9-55.

1999 Del terreno al espacio: planteamientos y perspectivas para la Arqueología del paisaje. CAPA, 6. Santiago de Compostela: Grupo de Investigación en Arqueología del Paisaje.

Criado Boado, Felipe, Victoria Villoch Vázquez y David Barreiro Martínez

2000 Arqueología y parques eólicos en Galicia: Proyecto marco de evaluación de impacto. CAPA, 5. Santiago de Compostela: Grupo de Investigación en Arqueología del Paisaje.

Di Vruno, Antonela, Anabela Diana, Verónica Seldes, María Teresita de Haro, Jimena Doval, Pablo Giorno y Lucía VÁzQuez

2006 «Arqueología en un centro clandestino de detención. El caso Mansión Seré Atila» Actas del $3^{\circ}$ Congreso de Arqueología Histórica, Rosario.

DeMarrais, Elizabeth, Luis Jaime Castillo y Timothy Earle

1996 «Ideology, materialization and power strategies». Current Anthropology 37 (1): $15-31$.

Doval, Jimena, Pablo Francisco Giorno, María Teresita de Haro y Anabela Noel DianA

2009 «Una reconstrucción arquitectónica desde la imagen fotográfica», en Mamül Mapu: pasado y presente desde la arqueología pampeana, M. Berón et al., eds., pp. 215-226. Buenos Aires: Editorial Libros del Espinillo.

EDWARDS, Elizabeth

2001 Raw Histories: Photographs, Anthropology and Museums. Oxford: Berg.

Foucault, Michael

1989 Vigilar y castigar. El nacimiento de la prisión. Madrid: Siglo XXI.

1992 La microfisica del poder. Madrid: La Piqueta.

FunARI, Pedro Paulo

1999 «Arqueología e historia. Arqueología histórica mundial y de América del sur». Anales de Arqueología y Etnología 50/51: 109-132.

FunARI, Pedro Paulo y Andrés Zarankin

2002 «Social Archeology of Housing from a Latin America Perspective». Journal of Social Archaeology 3 (1): 23-45.

Gallardo, Francisco, Mauricio Uribe y Patricia Ayala

1995 «Arquitectura Inka y poder en el Pukara de Turi, Norte de Chile». Gaceta Arqueológica Andina 24: 151-171.

GNecCo, Cristóbal

1999 Multivocalidad histórica: hacia una cartografía postcolonial de la arqueología. Bogotá: Universidad de los Andes.

Gómez Romero, Facundo

2006 «Fortines del desierto tecnologías de poder: una arqueología de vagos y mal entretenidos», en Estudios de Arqueología Histórica. Investigaciones argentinas pluridisciplinarias, A. Tapia, M. Ramos y C. Baldasarre, eds., pp. 43-73. Río Grande: Museo Municipal de la Ciudad de Río Grande. 
HiLlier, Bill y Julienne Hanson

1984 The Social Logic of Space. Cambridge: Cambridge University Press.

HODDER, Ian

1988 Interpretación en Arqueología. Barcelona: Editorial Crítica.

InSTITUTO HistóRICO DE MORÓN

1997 Entrevista a Osvaldo Paracone. Municipio de Morón. Manuscrito.

JoHnson, Matthew

1996 An Archaeology of Capitalism. Oxford: Blackwell Publisher.

LEONE, Mark

1984 «Interpreting Ideology in Historical Archaology: the William Paca Garden in Annapolis, Maryland», en Ideology, Power and Prehistory, D. Miller y C. Tilley, eds., pp 25-35. Cambridge: Cambridge University Press.

2005 The Archaeology of Liberty in American Capital. Excavation in Annapolis. Londres: University of California Press.

Mañana BorrazÁs, Patricia, Rebeca Blanco Rotea y Xurxo Ayán Vila

2002 Arqueotectura 1: bases teórico metodológicas para una arqueología de la arquitectura. TAPA, 25. Santiago de Compostela: Universidade de Santiago de Compostela.

MOORE, Jerry

1996 Architecture and Power in the Ancient Andes. The Archaeology of Public Buildings. Cambridge: Cambridge University Press.

NieLSEN, Axel

1995 «Architectural Performance and the Reproduction of Social Power», en Expanding Archaelogy, J. M. Skibo, W. H. Walker y A. E. Nielsen, eds., pp. 47-66. Salt Lake City: University of Utah Press.

Nielsen, Axel y William WaLKer

1999 «Conquista ritual y dominación política en el Tawantisuyu. El caso de Los Amarillos (Jujuy, Argentina)», en Sed non satiata. Teoría social en la arqueología latinoamericana contemporánea, A. Zarankin y F. Acuto, eds., pp. 153-169. Buenos Aires: Ediciones del Tridente.

ORSER, Charles

1988 «The Archaeological Analysis of Plantation Society: Replacing Status and Caste with Economics and Power». American Antiquity 53 (4): 735-751.

2000 Introducción a la arqueología histórica. Buenos Aires: Asociación Amigos del Instituto Nacional de Antropología.

SÁEz, Graciela

1998 «El tiempo de las quintas». Revista de Historia Bonaerense 17: 7-12.

SENATORE, Ximena

2004 «Discursos ilustrados y sociedad moderna en las colonias españolas de Patagonia (siglo XVIII)», en Arqueología histórica en América del sur. Los desafios del siglo XXI, A. Zarankin y P. Funari, eds., pp. 31-56. Bogotá: Ediciones Uniandes. 
Shanks, Michael y Christopher TILley

1987 Re-constructing Archaelogy. Theory and Practice. Cambridge. Cambridge University Press.

SCHAVELZÓN, Daniel

1991 Arqueología histórica de Buenos Aires. Buenos Aires: Corregidor.

1999 Arqueología de Buenos Aires. Buenos Aires: Editorial Emecé.

2005 Túneles de Buenos Aires: historias, mitos y verdades del subsuelo porteño. Buenos Aires: Sudamericana.

THOMAs, Julian

2001 «Archaeologies of Places and Landscape», en Archaeological Theory Today, Ian Hodder, ed., pp. 165-186. Cambridge: Polity Press.

Tilley, Christopher

1996 «The Power of the Rocks: Topography and Monument Construction on Boodmind Moor». World Archaeology 28 (2): 161-176.

ZARANKIN, Andrés

1999 «Casa tomada: sistema, poder y vivienda doméstica», en Sed Non Satiata. Teoría social en la Arqueología latinoamericana contemporánea, A. Zarankin y F. Acuto eds., pp. 239-272. Buenos Aires: Ediciones del Tridente.

Zarankin, Andrés y C. Niro

2006 «La materialización del sadismo. Arqueología de la arquitectura de los centros clandestinos de detención de la dictadura militar argentina (1976-1983)», en Arqueología de la represión y la resistencia en América Latina, 1960-1980, A. Zarankin y P. Funari, eds., pp. 159-182. Córdoba: Editorial Brujas.

WILKIE, Laurie

2006 «Documentary Archaeology», en Historical Archaeology, D. Hicks y M. Beaudry, eds., pp. 13-33. Cambridge: Cambridge University Press.

WeBMOOR, Timothy

2005 «El Patrimonio Cultural: estudio preliminar sobre las múltiples concepciones de Teotihuacan. Resumen del Proyecto». Tezontle: Boletín del Centro de Estudios Teotihuacanos. 